\section{Parcerias público-privadas (PPP) no setor saúde: processos globais e dinâmicas nacionais}

\author{
Public-private partnerships (PPPs) in the health \\ sector: global processes and national dynamics
}

\author{
Acuerdos de colaboración público-privados (CPP) \\ en el sector salud: procesos globales y \\ dinámicas nacionales
}

Celia Almeida 1

doi: 10.1590/0102-311X00197316

\section{Resumo}

Este ensaio se propõe a discutir algumas dimensões que impulsionam e consolidam a crescente participação de atores privados no processo de decisão na saúde, enfatizando elementos internacionais e domésticos que se potencializam e sustentam a permanência da perspectiva politico-ideológica neoliberal no setor ao longo de quase trinta anos (desde os anos 1990). Enfatiza-se o papel das organizações intergovernamentais nesse processo, ressaltando-se as interações público-privadas nos âmbitos global e doméstico, sobretudo das denominadas parcerias público-privadas (PPP). Parte-se da premissa que tais articulações alteram as relações de poder na formulação e implementação de politicas, com predominância dos agentes privados. Apresenta-se um breve panorama do desenvolvimento das PPP na Europa, na América Latina e no Brasil, resgatando-se suas origens específicas e simultaneidade de eventos desencadeadores. Reitera-se a importância de não se ignorar o poder desses atores, assim como a dificuldade de deslocá-los desse lugar político, uma vez envolvidos no processo decisório, seja nas organizações multilaterais, seja nos sistemas de saúde em nível nacional. A pretensão é enfatizar a importância de aprofundamento da reflexão sobre o assunto, subsidiando os debates setoriais. Toda essa dinâmica exige repensar estratégias de resistência para preservar direitos conquistados com lutas seculares.

Parcerias Público-Privadas; Sistemas de Saúde; Serviços de Saúde;

Política de Saúde

\section{Correspondência}

C. Almeida

Departamento de Administração e Planejamento em Saúde, Escola Nacional de Saúde Pública Sergio Arouca, Fundação Oswaldo Cruz.

Rua Leopoldo de Bulhões 1480, 7o andar, sala 722,

Rio de Janeiro, RJ 21041-210, Brasil.

calmeida@ensp.fiocruz.br

1 Escola Nacional de Saúde Pública Sergio Arouca, Fundação Oswaldo Cruz, Rio de Janeiro, Brasil. 


\section{Introdução}

Há praticamente três décadas, vive-se um processo de reformas econômicas neoliberais que tem provocado impactos negativos em todos os demais setores. E se constata, atualmente, uma revitalização radical dessas reformas, que tem sido vigorosamente promovida em níveis global e local.

O núcleo central das mudanças consiste nos ajustes macroeconômicos, diminuição drástica do gasto público, especialmente na área social, fortalecimento do mercado e privatizações. Essa dinâmica retoma a perspectiva liberal clássica na estruturação econômica e social, questionando o papel do Estado e alterando suas relações com a sociedade civil, ameaçando seriamente os direitos sociais conquistados 1,2. Entretanto, as estratégias e políticas internacionais e nacionais que engendram e consolidam a restrição de direitos e a privatização na área social, incluída a saúde, ainda são pouco analisadas no Brasil.

No setor saúde, especificamente nos sistemas de serviços de saúde, a gênese da agenda reformista formulada e implementada a partir dos anos 1980-1990, é conhecida 3. Sinteticamente, preconiza a retirada do Estado da provisão direta de serviços, a introdução de mecanismos de mercado na gestão dos sistemas públicos e privatizações. Mesmo no Brasil, concomitantemente à implementação do Sistema Único de Saúde (SUS), essas ideias foram incorporadas na reforma do Estado dos anos 19904.

A proposta deste Ensaio é discutir algumas dimensões importantes dessa dinâmica e o papel das instituições multilaterais nesse processo, mediante uma revisão da literatura. O foco está na redefinição das interações entre os setores público e privado, seja na arena internacional ou em âmbito doméstico, procurando-se analisar o papel que tem desempenhado ao longo do tempo no setor. A emergência das parcerias público-privadas (PPP) domina as discussões na saúde há tempos e será particularmente discutida.

Parte-se da premissa que a crescente participação de atores privados nos processos de decisão das organizações multilaterais e dos Estados nacionais é uma variável extremamente relevante, alterando as relações de poder na formulação e implementação de políticas. Esse fenômeno mundial aumentou muito nas últimas décadas e tem sido analisado com maior profundidade nas áreas econômica e de relações internacionais 5. Como isso se reflete no setor saúde? Quais as políticas e estratégias internacionais e nacionais que reforçam a difusão da agenda privatizadora e influenciam sua implementação?

Na primeira parte, descrevem-se as mudanças na arena internacional, destacando-se as inovações introduzidas desde a década de 1990. A seguir, apresenta-se o papel das agências da Organização das Nações Unidas (ONU) nessa dinâmica, com ênfase na Organização Mundial da Saúde (OMS), e o desenvolvimento das PPP em âmbito doméstico na Europa e na América Latina. Por fim, alinhavam-se algumas reflexões relevantes nesse processo, apontando o necessário aprofundamento dessas questões nos debates setoriais.

\section{Mudanças de atuação na arena internacional}

Desde a década de 1990, observa-se uma mudança paulatina na arena internacional, com aumento e diversificação de atores que circulam nesse âmbito, além dos Estados nacionais. Corporações privadas, fundações e organizações filantrópicas, organizações não governamentais diversificadas, entre outras, atuam nos fóruns internacionais ou junto às próprias agências da ONU. Argumenta-se que diferentes tipos de interação entre atores públicos e privados não constituem novidade na ONU 6, mas se constata uma inflexão importante com novos arranjos colaborativos entre eles 7,8,9.

A influência dos atores privados no processo decisório setorial (internacional e nacional) e na governança global da saúde (ou governança da saúde global) cresceu exponencialmente a partir do final dos anos 1990, com aumento de seu poder político e, simultaneamente, do crescimento de recursos para a saúde - na cooperação internacional e na ajuda externa -, frequentemente articuladas 6,7,8,9. 


\section{As PPP}

As PPP são apresentadas geralmente como uma estratégia inovadora 6,7,8. Segundo Buse \& Walt 6 a ideia de parcerias para o desenvolvimento não é nova, e o termo teria sido cunhado em 1969, no relatório da Comissão Pearson (Partners in Development: Report of the Commission on International Development), coordenada por Lester B. Pearson, ex-Primeiro Ministro do Canadá. Até os anos 1970, as colaborações público-privadas nas organizações multilaterais não existiam, mas algumas raras se estabeleciam diretamente entre doadores e governos nacionais.

Com a crise econômica dos meados dos 1970 e a ascensão mundial da perspectiva político-ideológica neoliberal, esse panorama começou a mudar. Capitaneados pelo Banco Mundial e o Fundo Monetário Internacional (FMI), os ajustes macroeconômicos estruturais dos anos 1980 e as reformas setoriais a eles condicionadas abriram espaço para o setor privado nas políticas públicas, com a supervalorização do mercado e da perspectiva empresarial, concomitantemente à desqualificação do Estado, das políticas sociais e da provisão de bens públicos 1, questionando-se a natureza pública de alguns bens (como a assistência médica). As PPP integram essa dinâmica.

Esse processo aumentou as desigualdades e a pobreza no mundo e, no final dos anos 1980 e início dos 1990, três dinâmicas contribuíram para a emergência e fortalecimento das PPP, vinculadas a mudanças no contexto da Cooperação Internacional para o Desenvolvimento (CID) e da ajuda externa $6,10,11$.

A primeira se refere à construção político-ideológica da pobreza como objeto das políticas internacionais. Previamente, acreditava-se que o crescimento econômico provocaria o "efeito derrame", alavancando a diminuição da pobreza, no entanto as evidências apontavam o contrário e o Banco Mundial formulou o "combate à pobreza" como foco central das políticas internacionais 10,12.

A segunda mudança contextual foi o descrédito nas agências da ONU, consideradas inefetivas e pesadas. A comunidade de doadores constatava os parcos resultados da CID e reivindicava uma agenda política de boa governança, formalizada em 1992 pelo Development Assistance Committee (DAC) da Organisation for Economic Co-operation Development (OECD), rediscutindo o papel do Estado e defendendo que o desenvolvimento seria alcançado com uma relação mais equilibrada entre o Estado, o mercado e o "terceiro setor" 1. Os princípios do novo "gerencialismo" público integram essa agenda que reforça o paradigma das parcerias na construção da governança global 13. No caso da OMS, o questionamento de sua capacidade de liderança setorial e o protagonismo de novos atores nessa arena internacional, como o Banco Mundial, impulsionaram o debate sobre a sua reforma 10,14.

A terceira mudança foi a difusão da ideia de que a complexidade dos problemas globais a serem enfrentados exigiria a participação de todos os atores, públicos e privados.

No final da década de 1990, o World Report 1997 do Banco Mundial pregava a baixa efetividade dos Estados nacionais na promoção do desenvolvimento, pois a globalização econômica exigiria um Estado diferente daquele estruturado no pós-guerra. Identificando como principal problema a falta de efetividade da condução estatal, alegava que, diferente do período pós-Segunda Guerra, o papel central do Estado não seria mais de alavancar o desenvolvimento econômico e social, ou de prover serviços diretamente, mas sim de catalisador e facilitador desse desenvolvimento. Advogava pela necessidade urgente de sua reforma, a fim de se adaptar às exigências e demandas de uma economia mundial globalizada, com uma estratégia de duas etapas: primeiro, focalizar sua ação nas tarefas essenciais que tivesse capacidade de executar e, depois, promover capacidade adicional por intermédio de parcerias com a comunidade empresarial e a sociedade civil 15. As agências e organizações internacionais poderiam encorajar e sustentar essas reformas, tanto proporcionando assessoria técnica quanto assistência financeira 15.

As PPP promoveriam a necessária ação conjunta, considerada positiva a priori. Os avanços tecnológicos, particularmente na área farmacêutica e de vacinas, influíram nessa mudança de percepção na saúde em nível internacional 9,11. Constituem um determinado tipo de interação público-privada, materializada primeiramente em nível internacional nas Iniciativas Globais em Saúde (Global Health Initiatives - GHI), tais como a Global Alliances for Vaccines and Immunizations (GAVI); o Global Fund to Fight AIDS, Tuberculosis and Malaria (GFTM), conhecido como Fundo Global; a Global Alliance for Improved Nutrition (GAIN); a Roll Back Malaria (RBM); a STOP TB, entre outras. Em nível local, 
as PPP têm sido valorizadas na provisão de serviços de saúde e as inovações introduzidas no National Health Service (NHS) inglês são a principal referência 16.

O termo PPP é utilizado de forma ampla, como um "guarda-chuva" 2 que abriga diferentes relações de colaboração entre atores públicos e privados para o alcance de objetivos (supostamente) comuns. Não é um conceito novo, mas não existe na literatura uma definição consensual 2.

Para o que nos interessa discutir aqui, é útil um breve repasse de algumas definições. Para Shäferhoff et al. 5, três critérios são recorrentes nas definições: a natureza dos atores, as metas, e a partilha de riscos e responsabilidades.

Muitos autores não fazem distinção entre os atores privados (lucrativos ou não) que integram essas parcerias 17, enquanto outros as restringem aos parceiros privados lucrativos, como um critério diferenciador das PPP 8; entretanto essa distinção não é claramente justificada. As metas a serem alcançadas - provisão de bens coletivos - seriam o segundo critério, que remete à importante debate: os bens coletivos têm pelo menos uma característica dos bens públicos - são benefícios não exclusivos e não rivais, o consumo de um não inviabiliza o de outros - diferem, porém, dos bens públicos porque podem estar destinados à determinada coletividade (exemplo, patentes). Portanto, a concepção de PPP como destinadas a resolver "problemas coletivos" é uma escolha política que não necessariamente se refere à provisão de bens públicos 5 . O terceiro critério - igual distribuição de ônus e bônus entre os parceiros - também é controverso, pois "o compartilhamento de riscos, responsabilidades, recursos, competências e benefícios” 17 (p. 46) não é consensual. Por exemplo, a OECD 18 define que as parcerias seriam uma relação baseada em acordos que refletiriam responsabilidades mútuas para o alcance de interesses compartilhados; as definições da OMS 19 e da ONU (Enhanced Cooperation Between the United Nations and All Relevant Partners, in Particular the Private Sector) seguem a mesma linha. Já o Banco Mundial afirma que "todas as partes [que integram as PPP] destinam recursos (financeiros, técnicos ou pessoal) para atividades acordadas, com clara divisão de responsabilidades e distintas accountabilities para o alcance de metas" 5 (p. 454). Assim, a corresponsabilidade nos riscos "é uma premissa normativa" que deve ser comprovada empiricamente 5 (p. 455).

Existem outras definições mais operacionais: "uma forma de cooperação estruturada entre parceiros públicos e privados para o planejamento ou construção elou a exploração de instalações nas quais compartem ou realocam riscos, custos, benefícios, recursos e responsabilidades" 2 (p. 2).

$\mathrm{Na}$ área de saúde, a definição mais utilizada de PPP global foi elaborada por Buse \& Walt 7 que, de forma genérica, as definem como arranjos particulares que não raro incluem uma terceira parte, tais como organizações não-governamentais (ONGs), grupos da sociedade civil, agências doadoras, além de "órgãos intermediários" para a gestão dos fundos ou a coordenação da articulação estabelecida.

Outros afirmam que as PPP na saúde constituem um "novo paradigma global e têm um arcabouço teórico subjacente" 20 (p. 8) cujo elemento-chave seria o "processo partilhado [especificamente com o setor privado lucrativo] de tomada de decisão", e, "nas parcerias mais estratégicas, os parceiros trabalham juntos em todos níveis e estágios da iniciativa, do desenho à governança, implementação e avaliação” 17 (p. 47).

Em sua revisão sistemática de várias definições, Torchia et al. 2 (p. 2) constatam que "as características mais significativas de uma PPP [na saúde] incluem: cooperação; relações duráveis; desenvolvimento de produtos/serviços mútuos; compartilhamento de riscos, custos e benefícios; e valor agregado mútuo". Comparadas com formas mais tradicionais de cooperação pública e privada, as PPP teriam três aspectos distintivos 2: (a) os parceiros não compartilham a propriedade dos meios de produção - de um lado está uma organização pública como o Estado e, do outro, uma empresa privada lucrativa; ambos os parceiros tenderiam, portanto, a perseguir diferentes metas e implementar distintas estratégias; (b) os produtos das PPP são sempre bens públicos ou quase públicos, como serviços, e estão voltados para o benefício de uma terceira parte, que pode ser o Estado, a sociedade ou os usuários de determinado serviço de saúde; e (c) em geral são formuladas para existir durante longos períodos de tempo, geralmente mais de uma década. Outras premissas também orientam esse "paradigma": as relações devem ser baseadas na "confiança" e buscar "benefícios mútuos" em que "todos ganham" 20. Esses arranjos seriam "inevitáveis" e "imperativos" 2. Não existem, porém, estudos que demonstrem claramente que as PPP são mais eficientes e custo-efetivas que a provisão pública direta de serviços e, como regra, as decisões sobre os contratos (concessões) não são precedidas dessa avaliação.

Outro elemento a ser considerado é a não distinção entre os diferentes atores sociais que atuam na arena internacional, uma vez que todos são chamados parceiros, indiscriminadamente, indepen- 
dentemente de seus papeis na sociedade. Essa pretensa uniformidade esconde o fato de que os atores públicos e os distintos atores privados não têm o mesmo status, nem os mesmos objetivos e interesses, o que relativiza o papel legal das organizações públicas intergovernamentais, assim como sua legitimidade 1,9. Por conseguinte, o termo parceiro tem conotação eminentemente política, assim como a advocacia das parcerias.

Em síntese, as PPP globais e nacionais em saúde tornaram-se um mecanismo-chave para a implementação das políticas sociais, como parte das estratégias de consolidação da "nova ordem econômica neoliberal global", que inclui uma profunda mudança na forma como atores públicos se articulam com o setor privado e na maneira como os atores privados atuam frente ao setor público 1. Constituem novas formas de privatização, com consequências na provisão de serviços como bens públicos, e precisam ser mais bem estudadas e monitoradas, dada sua proliferação mundial.

\section{A ONU e as interações público-privadas}

A OMS interagiu com o setor privado desde seus primórdios, da mesma forma que outras agências da ONU. Embora a referência à "parceria" na organização remonte ao início dos anos 1990, não tinha a conotação que lhe foi atribuída posteriormente, pois se referia a mecanismos utilizados para impulsionar as metas de "saúde para todos no ano 2000" e de desenvolvimento sustentável 4.

Richter 20 afirma que a Conferência sobre Meio Ambiente e Desenvolvimento (a Cúpula da Terra), realizada no Rio de Janeiro em 1992, marcou o início da inflexão da ONU na direção de uma relação mais próxima com o setor privado lucrativo, que participou ativamente na organização e teria influenciado a elaboração da Agenda 21. Os relatórios da United Nations Inspection Joint Unit apontavam, desde o início da década de 1990, a necessidade de incrementar a colaboração institucional entre os parceiros da CID, inclusive não governamentais, para que a ONU pudesse colaborar mais efetivamente com as instituições financeiras multilaterais 20.

A eleição de Kofi Annan como Secretário-Geral das ONU, em dezembro de 1996, institucionalizou as "parcerias com a indústria", como parte das reformas da Organização. Enfatizava-se também o papel da sociedade civil nesse processo, referida em sentido amplo, "não apenas como difusora de informações, ou provedora de serviços, mas também como participante da formulação de políticas" 21 (p. 71). Em janeiro de 1998, no Fórum Econômico Mundial, em Davos, Suíça, o secretário reconhecia que a paz e a prosperidade não poderiam ser alcançadas sem parcerias entre vários setores da sociedade, incluídas as empresas lucrativas 20,21. Esperava-se que tais parcerias fortalecessem os cofres da organização, com maior engajamento, inclusive financeiro, na sua missão institucional, na linha do que Kofi Annan chamaria pouco tempo depois uma globalização com face humana 21.

Na administração de Gro Brundtland (1998-2003) na OMS, esse discurso se concretiza 10,14, sendo a primeira organização da ONU a fazê-lo 22 . Historicamente, a OMS e outras agências da ONU enfrentaram pressões de atores privados e de Estados-membros, como Estados Unidos, seu maior financiador, que cortava sua contribuição quando as políticas das agências não o agradavam. Por exemplo, em 1997 os Estados Unidos suspenderam suas contribuições regulares 22 e, no caso da OMS, houve momentos de quase congelamento orçamentário desde os anos 1980 10,14.

Antes de ser eleita diretora da OMS, Brundtland foi Primeira Ministra da Noruega nos anos 1980 e 1990 e coordenou a Comissão Mundial sobre Ambiente e Desenvolvimento, cujas recomendações pautaram a Cúpula da Terra em 1992. Endossava desde então a política da "terceira via" do novo trabalhismo de Tony Blair, Primeiro Ministro do Reino Unido no período 1997 a 2007. Uma vez eleita, começou a remodelar a OMS, segundo as linhas da agenda neoliberal 10,14,22. No seu primeiro discurso na Assembleia Mundial da Saúde (AMS), a nova diretora afirmou seu compromisso de "estabelecer relações com o setor privado lucrativo, como meta de seu secretariado" 20 (p. 13).

Como uma de suas primeiras medidas, Brundtland implantou uma reforma administrativa na qual desativou ou mesclou várias unidades, estruturando os chamados clusters temáticos 9,10,14. Como orientação geral, adotou o relatório do Banco Mundial de 1993 - Investing in Health. Muitos dos autores desse relatório foram para a OMS para estabelecer a nova Unidade de Evidências e Informação para a Política, quase um "ramo de Harvard e do Banco Mundial" 22, dirigida por Julio Frenk, médico sanitarista mexicano vinculado ao Banco Mundial e a outros poderosos atores privados norte-americanos. 
Em janeiro de 2000, a diretora estabeleceu a Comissão de Macroeconomia e Saúde com a tarefa de analisar o papel da saúde no desenvolvimento econômico global. Esta Comissão foi financiada por vários países centrais e pela Fundação Bill e Melinda Gates e coordenada por Jeffrey Sachs. O relatório final, lançado em dezembro de 2001 (Macroeconomics and Health: Investing in Health for Economic Development), recomendava a reorientação do trabalho da OMS: exaltava os benefícios dos novos mecanismos de financiamento (o modelo das GHI); encorajava a participação de poderosos atores privados, como a indústria farmacêutica, no processo de decisão nas questões de saúde e explicitava preocupação com "potencial conflito de interesse", não como salvaguardas, mas como possíveis "constrangimentos” à implementação de uma forma inovadora de trabalho 8. Mesmo que muito criticado, o relatório da Comissão de Macroeconomia e Saúde se tornou a bússola de Brundtland.

Em maio de 2000, Brundtland lançou a Civil Society Initiative (CSI) na AMS, na perspectiva de facilitar os aportes das ONGs em nível global. Essa iniciativa atualizava uma outra normatização de 1987 (Principles Governing Relations berween the World Health Organization and Nongovernamental Organizations), que propunha formalizar as consultas a amplo leque de atores, promovendo interações mais efetivas com a sociedade civil, incluindo movimentos sociais, associações voluntárias, ONG, organizações de base e outros atores sem fins lucrativos.

Em novembro do mesmo ano (2000), a Diretora Geral decidiu aprovar o Guidelines for Interaction with Commercial Enterprises como um instrumento gerencial, sem passar pela discussão na AMS e, apesar dos protestos dos Estados-membros e de ONG que participavam das reuniões do Executive Board (EB), assim como de participantes de um seminário internacional promovido pela própria OMS nesse ano (International Seminar on Global Public-Private Partnerships for Health and Equity). Recusou ainda a sugestão do EB de colocar em consulta pública a proposta de um documento de orientação para as articulações público-privadas 20. E, no final de 2002, outro documento sobre o tema foi lançado (Policy for Relations between the World Health Organization and Nongovernmental Organizations), propondo uma política institucional específica.

Nenhuma dessas propostas definia o que se incluía como ONG. A última, de 2002, foi objeto de várias discussões e objeções no EB e na AMS de 2003, sendo defendida pelos Estados Unidos e pelas associações das indústrias, com o argumento de que todas as organizações que não fossem públicas, ou não pertencessem ao Estado, deveriam ter o mesmo status (não governamental), caso contrário seria uma "discriminação injusta" 20 (p. 54). Como não se conseguiu nenhum acordo na AMS, foi criado um grupo de trabalho constituído por Estados-membro, cujo relatório foi apresentado em 2004, na gestão de Jong-wook Lee. O termo foi mantido, assim como a não diferenciação entre as organizações abrangidas por essa denominação; foram incluídos alguns parágrafos sugerindo que a OMS deveria elaborar diretrizes claras para evitar conflitos de interesse e salvaguardar sua integridade e independência institucional 20. Porém, a AMS de 2004 não aprovou essa política.

Historicamente, os atores privados representantes das corporações se utilizavam da definição de ONG de 1946, elaborada na criação da ONU, e frequentemente requeriam e conseguiam obter o direito de participar das consultas públicas e das discussões nas agências multilaterais. O UN's Economic and Social Council (ECOSOC) aprovou, em 1996, uma resolução institucionalizando a relação consultiva entre a ONU e as ONG (Consultative Relationships between the United Nations and Non-governmanetal Organizations), e elas deveriam atuar em conformidade com o espirito, propósitos e princípios da Carta da ONU. Frente a recusas de inclusão de organizações vinculadas ao setor privado lucrativo, os atores reagiram criando suas associações representativas, por definição não lucrativas, encaixando-se nos requisitos normatizados.

A partir de 2000, a OMS havia saído da crise financeira, não pelo aumento das contribuições regulares, mas sim pelo grande crescimento dos recursos extraorçamentários 10,14. Esses financiamentos são doações voluntárias de Estados ou de atores privados para financiar programas e atividades especificas, cuja implementação é delegada a uma "terceira parte" (quase sempre ONG transnacionais) 23. Não estão submetidos à discussão e aprovação na AMS e, consequentemente, não integram os planos de trabalho da organização; têm objetivos e metas próprias, com "foco no problema”, segundo as percepções dos financiadores sobre qual é o problema e o foco a ser atacado para resolvê-lo 8,14.

Em síntese, os anos da administração de Brundtland (1998-2003) foram marcados por tensões permanentes em torno de decisões polêmicas, especialmente em relação à articulação entre atores públicos e privados. Ainda que tenha exercido uma única gestão, o que não é comum na 
OMS, seu legado, construído em perfeita sintonia com as opçoes político-ideológicas da época, permanece vigente.

\section{As PPP em nível nacional}

Os antecedentes das PPP nacionais nos sistemas de saúde remontam às reformas contemporâneas dos anos 1980-1990, que introduziram mecanismos de mercado (competição) na organização e gestão dos serviços públicos 16 .

O rationale subjacente está nas propostas de reforma do Estado contemporâneo. Desde os anos 1980-1990, com a crise econômica e do welfare e a dominância neoliberal, recomendou-se primeiro a desestatização e o fim do Estado provedor. Com o aumento das desigualdades e da pobreza no mundo, fortaleceu-se a perspectiva do Estado regulador, na economia e na área social (regulação social), e de prestador de bens públicos mínimos e transitórios, privilegiando-se a condição individual. Nesse enfoque, a função primordial do Estado seria de promotor do desenvolvimento humano e comunitário, aguçando sua capacidade de "agente conciliador dos conflitos imanentes à sociedade policêntrica atual, não somente estabelecendo canais de participação e interlocução com seus representantes (...) mas criando vínculos, acordos, alianças e parcerias com entidades empresariais e sociais" 24 (p. 7). O "Estado contratual contemporâneo" substituiria o "Estado administrativo-burocrático, hierárquico (...) e gestor direto" 24 (p. 8) por um novo tipo de administração pública, com formas jurídicas diferentes dos contratos administrativos tradicionais. As PPP no setor saúde se inserem nessa dinâmica.

\section{Desenvolvimento das PPP na Europa}

As organizações precursoras das PPP na Europa surgem no Reino Unido, e a referência está nas mudanças introduzidas no NHS inglês no governo neoconservador de Margareth Thatcher, no início dos anos 1990, cujo modelo de reforma se difundiu como paradigma para a Europa e outras regiões, ainda que operacionalizado de diferentes formas em cada país 16,25. Essas PPP ganharam impulso a partir de 1997, quando os trabalhistas voltaram ao poder 16,26, e continuam até hoje independentemente do partido no poder.

O processo se inicia com os NHS Trusts constituídos na reforma de Thatcher como organizações autônomas não lucrativas, operando como empresas independentes sob contratos, competindo pelo financiamento público. A autonomia dos trusts foi aumentada com a sua transformação em fundações privadas (Foundation Trusts); e as Private Finance Initiaves (PFI), em que o poder público contrata a compra de serviços em longo prazo, foram impulsionadas na saúde 25,27 . As PFI financiam infraestrutura, serviços de manutenção e apoio nos hospitais ("bata cinza"), mediante contratos de arrendamento, além de reformas e construções, não apenas em hospitais. Esse elenco de atividades vem aumentando, incluindo outros serviços de apoio e cirurgias eletivas. Para André \& Hermann 25, a partir de então se pode falar em PPP no Reino Unido e também na sua difusão para outros países europeus, sobretudo na área hospitalar.

A criação dos Independent Treatment Centres-Programme para procedimentos específicos, em 2000, incrementou o envolvimento privado no NHS. Conduzidos por empresas estrangeiras de assistência médica, atraiu profissionais do sistema público, provocando uma drenagem interna de recursos humanos do público ao privado, mesmo que no acordo estivesse explícito que a mão-de-obra deveria ser estrangeira 25. O modelo inglês de PPP não envolve serviços clínicos (bata branca), entretanto, em outros países, as PPP englobam ambos serviços (bata cinza e branca), como por ex. em Portugal e na Espanha (Figura 1).

A literatura sobre a implementação das PPP ainda é escassa, mas a revisão sistemática de Torchia et al. 2 apresenta alguns achados. As PFI são a principal fonte de investimento de capital no NHS. O sistema de saúde italiano (Servizio Sanitario Nazionale - SSN), por sua vez, é o segundo maior mercado de PPP na Europa; sua implementação deslanchou a partir de 2002, utilizando o modelo inglês da PFI. Na Espanha, a maioria das PPP segue o modelo das concessões e dos contratos da administração pública; o processo é complexo e consiste em cinco etapas: pesquisa, estudos de viabilidade e esboço 
Figura 1

Tipos de parcerias público-privadas (PPP) e implementação em países na Europa.

\begin{tabular}{|c|c|}
\hline Tipo de parceria/Países & Descrição \\
\hline $\begin{array}{l}\text { Private Finance Initiative (PFI) também denominada } \\
\text { Design-Build-Operate-Transfer (DBOT)/Reino Unido, } \\
\text { Espanha, Itália, França, Suécia, Austrália, Portugal } \\
\text { (depois de 2008) }\end{array}$ & $\begin{array}{l}\text { É a forma mais comum de PPP na saúde, modelo utilizado para a construção de hospitais } \\
\text { no Reino Unido e outros países europeus. Envolve o financiamento pelo setor público de } \\
\text { serviços construídos e/ou mantidos gerencialmente pelo setor privado. No final do prazo } \\
\text { contratual, transfere o serviço para o setor público. O setor privado é responsável pelos } \\
\text { serviços de apoio, hotelaria e gestão; o setor público é responsável pela prestação de } \\
\text { serviços assistenciais. Em alguns casos, há cobrança de taxas de utilização dos usuários, } \\
\text { como parte complementar do financiamento ou recuperação de custos. }\end{array}$ \\
\hline Joint Ventures/Áustria & $\begin{array}{l}\text { Parceiros públicos e privados ou privados não lucrativos juntam seus ativos, recursos } \\
\text { financeiros e expertises para uma gestão conjunta de determinado serviço. }\end{array}$ \\
\hline $\begin{array}{l}\text { PPP para provisão de serviços assistenciais } \\
\text { específicos/Reino Unido, Espanha, Alemanha, } \\
\text { Romênia }\end{array}$ & $\begin{array}{c}\text { O setor público contrata agentes privados para oferta de serviços específicos que } \\
\text { envolvem grande incorporação de alta tecnologia, como diálise, rádio e quimioterapia, } \\
\text { exames diagnósticos por imagem, cirurgias eletivas etc. }\end{array}$ \\
\hline $\begin{array}{l}\text { Public-private Integrated Partnerships (PPIP) ou } \\
\text { Design-Build-Operate-Deliver (DBOD)/Espanha e } \\
\text { Portugal (até 2008) }\end{array}$ & $\begin{array}{l}\text { O agente privado é responsável por todo o processo de construção e gestão geral, } \\
\text { além da provisão de serviços assistenciais em uma ou mais unidades, frequentemente } \\
\text { incluindo um hospital geral para enfermidades agudas, como também ambulatórios, } \\
\text { serviços laboratoriais de diagnóstico etc. }\end{array}$ \\
\hline
\end{tabular}

Fonte: elaboração própria com base em Torchia et al. 2; André \& Hermann 25; Vicente-Fuentes 27; Llumpo et al. 33 e Giovanella \& Stegmüller 41.

das condições contratuais, abertura do projeto aos interessados, processo de licitação e escolha. Na Índia, o setor privado é dominante e a principal avaliação encontrada considera que as PPP "mitigaram positivamente a predominância do setor privado no sistema de saúde" 2 (p. 19).

A proliferação dessas iniciativas levou à emergência de multinacionais europeias na assistência médica, com origem em diferentes países e subsidiárias em outros. A tendência é de concentração, por meio de aquisições e fusões. Constata-se ainda o aumento das privatizações com a venda de hospitais públicos para investidores privados, assim como a construção de novos hospitais privados para procedimentos que utilizam alta tecnologia. Embora na Europa a fatia desse mercado fosse inicialmente limitada, verifica-se seu crescimento 26,28 .

\section{Desenvolvimento das PPPs na América Latina}

Na América Latina, as PPP operam desde os anos 1980 nos setores de transporte, telecomunicações e energia e, a partir dos meados de 2000, passaram a atuar também na "infraestrutura social", inclusive na saúde, segundo os mesmos modelos europeus 29.

Os antecedentes das novas PPP também remontam às reformas dos anos 1980-1990, sendo o Chile a vanguarda regional. A implementação da competição administrada (managed competition) nas reformas dos sistemas públicos de saúde teve grande penetração na região, de diferentes maneiras nos distintos países, em razão tanto dos ajustes econômicos que diminuíram os recursos públicos na área social, quanto das conjunturas políticas críticas (autoritárias, num primeiro momento, e democráticas com especificidades, posteriormente) $3,16,30,31$.

O financiamento público se manteve (como contribuições sociais obrigatórias - seguros nacionais de saúde), particularmente no Chile e Colômbia, considerados paradigmáticos, mas grande parte da provisão ficou a cargo de empresas privadas especialmente criadas, que recebem e gerenciam os recursos por captação (livre escolha dos segurados) para prestação de pacotes de serviços pré-defini- 
dos e oferecem seguros privados complementares à cobertura oficial. Atuam segundo a perspectiva de lucro e não de prestação de um bem público. Criaram-se assim grandes redes de provedores privados que competem por afiliados, vinculadas a corporações privadas (nacionais e internacionais), isto é, fortes mercados privados financiados por Estados com baixa capacidade de regulação.

Em vários países, a terceirização com organizações privadas para serviços específicos (hotelaria hospitalar, gestão) foi intensificada, alterando o mix público-privado tradicional de serviços. Aumentaram também os seguros privados de saúde 28,32 e o gasto privado direto das pessoas 26,33. Contudo, esses arranjos não são denominados PPP.

As tecnocracias nacionais foram atores cruciais nesses processos de reforma, como no Chile e na Colômbia 26. No Chile, refere-se à influência dos chamados Chigago Boys, economistas chilenos formados na "escola de Chicago", que defendiam a agenda neoliberal, e a ditadura de Pinochet permitiu a mudança radical do sistema de saúde sem qualquer oposição, por causa da repressão. Na Colômbia, registra-se a decisão das elites políticas de aprovar no Congresso Nacional, em 1993, uma reforma cujo modelo foi elaborado por consultores latino-americanos do Banco Mundial 29,34, assim como de convocar o apoio de Harvard para a sua implementação 34.

Simultaneamente ao aumento da cobertura populacional desses sistemas de saúde, cresceram as dificuldades de implementação (déficits, seleção de segurados, fechamento de hospitais, corrupção etc.), tanto quanto as ações judiciais pelo não cumprimento dos pacotes acordados, sobretudo na Colômbia, impulsionando um forte movimento social contra a reforma, envolvendo profissionais de saúde, universidades e associações da sociedade civil, protagonizando grandes embates com o governo e alcançando alguns avanços regulatórios, mas sem conseguir modificar o sistema e deslocar o poder dos atores privados.

No Chile, com a democratização no início dos anos de 1990, e após anos de debates e do trabalho de três comissões nacionais de reforma da reforma - sendo a última conformada desde 2010 (Comisión Asesora Presidencial para el Estudio y Propuesta de un Nuevo Marco Jurídico para el Sistema Privado de Salud) e convocada em 2014 pela Presidente Bachelet -, conseguiu-se ampliar os procedimentos nos pacotes contratados com as entidades privadas (ISAPRES) e aumentar a regulação, com altos custos de transação, no entanto o setor privado mantêm-se estável 30,31.

Llumpo et al. 33 apresentam um panorama sobre o "mercado das PPP" na assistência à saúde em 17 países na região. Na última década, muitos países aprovaram legislações sobre o tema, ou estão em processo de aprovação, e o México foi o pioneiro a implementar PPP propriamente ditas; o Chile começou a implementá-las em 2009, mas parou em 2014; o Peru é o país que aderiu mais recentemente; e a Colômbia teria legislação aprovada (Figura 2).

Enfatiza-se que essa alegada expansão das PPP na região não tem sido adequadamente acompanhada nem suficientemente debatida. Fica a dúvida de quão "silencioso" tem sido esse processo de aprofundamento das privatizações na América Latina.

No Brasil, data de 1998 o estabelecimento no setor saúde de relações contratuais público-privadas diferentes dos contratos administrativos tradicionais (previstos nas Leis no 8.666 de 1993 e $n \underline{o}$ 8.987, de 1995). Os primeiros são denominados Contratos de Gestão: uma relação entre o Estado e organizações sem fins lucrativos, denominadas Organizações Sociais - OS (1998) ou Organizações da Sociedade Civil de Interesse Público - OSCIP (1999), com requisitos de qualificação, pactuação de metas e controle da sociedade civil 35.

As OS têm forte oposição setorial, seja por questões ideológicas, seja por problemas de descumprimento das cláusulas contratuais. Mesmo assim, em 2015, após vinte anos de sua criação, essas organizações foram consolidadas legalmente por decisão do Supremo Tribunal Federal (STF), que considerou as parcerias com a iniciativa privada como "opções constitucionalmente admitidas para a prestação de serviços públicos" 36 (p. 4). A interpretação constitucional acolhida pelo STF em 2016 inverte a lógica vigente até então ao declarar "a supremacia do direito fundamental à saúde em detrimento de determinado modelo estatal de prestação de serviços" 36 (p. 7).

A lei que instituiu nacionalmente as PPP - utilizando esse nome pela primeira vez - é de 2004 e define normas gerais para a licitação e a contratação de PPP em todos os níveis de governo, ainda que alguns estados já houvessem aprovado leis sobre o tema (Minas Gerais, 12/2003; Santa Catarina, 02/2004; Goiás, 08/2004; Ceará, 12/2004), ou a aprovaram logo após (Rio Grande do Sul, 01/2005) 24 (p. 21). 
Figura 2

Situação do desenvolvimento de parcerias público-privadas (PPP) na América Latina, 2015.

\begin{tabular}{|c|c|c|}
\hline País & Situação atual da legislação & Vontade política e efetivação de projetos \\
\hline México & $\begin{array}{l}\text { Legislação aprovada em nível } \\
\text { federal e/ou local. }\end{array}$ & $\begin{array}{l}\text { Foi o primeiro país a desenvolver projetos de PPP, desde } 2005 \text {, e agressivamente } \\
\text { implementou } 10 \text { projetos com duração de } 10 \text { anos. É também o único que tem projetos } \\
\text { em andamento desde então, com forte apoio político. Todos os projetos são do tipo } \\
\text { Design-Build-Operate-Transfer (DBOT). Desde o início enfrentou dificuldades - baixa taxa } \\
\text { de ocupação, recrutamento e retenção de profissionais. }\end{array}$ \\
\hline Chile & $\begin{array}{l}\text { Legislação aprovada em nível } \\
\text { federal e/ou local. }\end{array}$ & $\begin{array}{l}\text { Inicio de desenvolvimento das PPP no governo de Ricardo Lagos, tendo feito concurso } \\
\text { para } 5 \text { hospitais no modelo Design-Build-Operate-Transfer (DBOT) com } 15 \text { anos de } \\
\text { duração. Mas, desde 2014, com a mudança de governo, houve parada desses processos } \\
\text { por problemas apontados na avaliação pela posição governamental negativa a esses } \\
\text { investimentos privados. }\end{array}$ \\
\hline Peru & $\begin{array}{l}\text { Legislação aprovada em nível } \\
\text { federal e/ou local. }\end{array}$ & $\begin{array}{l}\text { Foi o último país a implantar PPP (2010), experimentando diferentes modelos, mas } \\
\text { também de forma mais ousada, sendo o primeiro a contratar PPP e a incluir serviços de } \\
\text { PPP para atenção de doenças crônicas. }\end{array}$ \\
\hline Colômbia & $\begin{array}{l}\text { Legislação aprovada em nível } \\
\text { federal e/ou local. }\end{array}$ & $\begin{array}{l}\text { PPP têm forte apoio político, a própria reforma do sistema de saúde do início dos anos } \\
1990 \text { implementou um tipo de PPP muito particular; ao mesmo tempo existe forte } \\
\text { resistência dos movimentos sociais ao modelo e algumas alterações no pacote de atenção } \\
\text { têm sido aprovadas sem, entretanto, mudar o sistema. }\end{array}$ \\
\hline $\begin{array}{l}\text { Honduras } \\
\text { Nicarágua } \\
\text { Costa Rica } \\
\text { Uruguai } \\
\text { Paraguai }\end{array}$ & $\begin{array}{l}\text { Legislação aprovada em nível } \\
\text { federal e/ou local. }\end{array}$ & Existe interesse nos investimentos privados, mas as PPP em saúde não são prioridade. \\
\hline $\begin{array}{l}\text { Guatemala } \\
\text { Venezuela } \\
\text { Equador } \\
\text { Bolívia } \\
\text { Argentina }\end{array}$ & $\begin{array}{l}\text { Nenhuma legislação referente } \\
\text { à PPP ou qualquer estrutura } \\
\text { formal parecida. }\end{array}$ & Posição negativa em relação aos investimentos privados no setor e às PPP. \\
\hline
\end{tabular}

Fonte: elaboração própria com base em dados e informações de Llumpo et al. 32.

Essas PPP são definidas na lei como: “... o contrato administrativo de concessão, na modalidade patrocinada ou administrativa (Art. 2). A concessão patrocinada é a concessão de serviços públicos ou obras públicas de que trata a Lei 8.987, de 1995, quando envolver adicionalmente à tarifa cobrada dos usuários contraprestação pecuniária do parceiro público ao parceiro privado (\$ 1 o do art. 2o). (...) a concessão administrativa é o contrato de prestação de serviços em que a Administração Pública seja usuária direta ou indireta, ainda que envolva execução de obras ou fornecimento e instalação de bens (\$ 2o do art. 2o)” 37 (grifos meus).

Estão voltadas para investimentos de grande porte e alto custo (como infraestrutura, hospitais) e a tônica está na ampliação das bases da negociação entre os parceiros "de forma menos rígida e verticalizada” 24 (p. 22). Ambos os tipos de PPP têm três características: (a) prazo de vigência de 5 a 35 anos; (b) valor total superior a R\$ 20 milhões, diluído no período contratual; e (c) requisitos prévios à formalização do contrato - estudos de conveniência, oportunidade e viabilidade financeira; análise de necessidades; comparações com alternativas; e justificativa da opção. É admitida a participação dos agentes privados na fase de preparação dos projetos - denominada de Procedimento de Manifestação de Interesse (PMI) -, com apresentação de documentos técnicos, jurídicos e financeiros 24 . A legislação brasileira inspirou-se nas PFI inglesas, e os procedimentos contratuais assemelham-se aos do modelo espanhol. 
Segundo Oliveira 24, o princípio subjacente às PPP seria a ampliação da capacidade de investimento do setor público, em que a autoridade pública continua responsável pelo serviço prestado ao cidadão, mas não necessariamente por todo o investimento. $\mathrm{O}$ desembolso de recursos públicos é diluído no tempo e se inicia após a disponibilização da infraestrutura criada e cumpridas as exigências contratuais pelo parceiro privado. O processo de decisão é complexo em todas as fases: a lei institui um Comitê Gestor da Parceria Público-privada (CGP) e Fundos Garantidores das PPP (FGP), de natureza privada e patrimônio próprio, para garantia das contraprestações 35 .

A primeira PPP criada no Brasil foi o Hospital de Subúrbio (HS) na Bahia, cuja chamada pública e PMI foi em 2009 e o início das atividades em 2010 38. É uma PPP integral em que a concessionária é responsável tanto pela gestão predial e administrativa (bata cinza) quanto pelo atendimento médico aos usuários (bata branca). O Hospital do Subúrbio opera sob o comando da empresa Prodal Saúde S.A., fruto de uma parceria entre a brasileira Promédica, especializada em serviços de saúde, e a francesa Dalkia, especializada em serviços de facilities e projetos de infraestrutura 36. Comprada em 2013 pelo fundo Axxon e por investidores minoritários, passou a se chamar Vivante. A empresa ganhou a licitação para operar por dez anos, renováveis por mais dez, e investiu R\$ 36 milhões na implantação do Hospital, além dos R\$54 milhões financiados pelo agente público ${ }^{36}$. No final do contrato, todos os bens que integram a estrutura do local serão revertidos ao Governo do Estado da Bahia.

O projeto enfrenta grande oposição de médicos do setor público e servidores da área de saúde no estado e é alvo de críticas, mesmo sendo reconhecido o sucesso do empreendimento: melhor qualidade assistencial, custos mais baixos e primeira instituição "pública" do Norte e do Nordeste a receber o Certificado da Organização Nacional de Acreditação (ONA nível 2) 38.

Barbosa \& Malik 35 analisaram processos de PPP na saúde no Brasil, no período 2010-2014, para vários tipos de serviços. Identificaram cerca de 47 PPP distribuídas em 12 municípios de diferentes estados, destacando-se São Paulo, Distrito Federal e Rio de Janeiro.

Existe também em execução no Brasil outro tipo de PPP que não se encaixa no modelo descrito acima. Trata-se do Programa de Apoio ao Desenvolvimento Institucional do Sistema Único de Saúde (PROADI-SUS) 39, cuja criação está vinculada às isenções fiscais concedidas a entidades filantrópicas em 1993. Sinteticamente, em 1998, decreta-se que as entidades filantrópicas da saúde (sobretudo hospitais) têm a possibilidade de se beneficiarem de isenções de pagamento de todos os impostos e contribuições sociais ao aplicarem esses recursos em projetos de desenvolvimento do SUS por meio de contratos com o Ministério da Saúde, depois de habilitados como Hospitais de Excelência. Tal disposição legal foi regulamentada e implementada a partir de 2006, com subsequentes atualizações, sendo as mais importantes as de 2009, 2010 e 2011 (Figura 3).

Nas atualizações legais, os Hospitais de Excelência podem, inclusive, substituir os $60 \%$ de sua atividade assistencial prestada ao SUS (antes obrigatórios e pagos pela tabela do Ministério da Saúde) pela aplicação nesses projetos em áreas estratégicas do SUS. O processo de apresentação, julgamento e aprovação dos projetos está a cargo do Departamento de Ciência e Tecnologia (DECIT), da Secretaria de Ciência, Tecnologia e Insumos Estratégicos (SCTIE) do Ministério da Saúde, com participação de outras áreas temáticas do próprio Ministério da Saúde. O Comitê Gestor inclui representantes das agências nacionais reguladoras, do Conselho Nacional de Secretários de Saúde (CONASS) e Conselho Nacional de Secretarias Municipais de Saúde (CONASEMS) (Figura 3).

Os projetos aprovados se articulam com redes de pesquisa clínica e instituições formadoras e focam em pesquisa clínica, uso e avaliação de tecnologias complexas, muitas delas não disponíveis no SUS, e na capacitação de gestores. Seis grandes hospitais foram habilitados - cinco de São Paulo/ capital e um de Porto Alegre (Rio Grande do Sul). O primeiro ciclo de projetos foi executado no triênio 2009-2011: cerca de 40\% foram aprovados para o Hospital do Coração, seguido do Hospital Alemão Oswaldo Cruz (26\%) e do Hospital Israelita Albert Einstein (16\%) 39. Foi realizado um seminário de discussão dos projetos desse triênio em 2011, com relatório publicado em 201240.

Ainda é cedo para avaliações mais conclusivas, entretanto citam-se alguns alertas. No caso das PPP de concessão administrativa, mencionam-se: os questionamentos e dificuldades enfrentadas na implementação do SUS e a especificidade histórica de seu mix público-privado, que privilegiou o setor privado; e a complexidade do desenvolvimento de projetos de PPP, que exige capacidade de diálogo e negociação, para acomodar os múltiplos atores e díspares interesses envolvidos, e de regulação, ambas incomuns no setor público 35. Quanto ao PROADI-SUS, poderia ser considerado uma alternativa de 
Figura 3

Institucionalização e regulamentação do Programa de Desenvolvimento Institucional do Sistema Único de Saúde (PROADI-SUS).

\begin{tabular}{|c|c|}
\hline Legislação: Tipo & Descrição/Definições \\
\hline $\begin{array}{l}\text { Decreto no 2.536, } \\
\text { de 07/Abr/1998 (conhecido } \\
\text { como Regulamento } \\
\text { da Filantropia): Dispõe } \\
\text { sobre a concessão do } \\
\text { Certificado de Entidade de } \\
\text { Fins Filantrópicos a que } \\
\text { se refere o inciso IV do } \\
\text { art. } 18 \text { da Lei no } 8.742 \text {, de } \\
\text { 07/Dez/1993, e dá outras } \\
\text { providências. }\end{array}$ & $\begin{array}{l}\text { Determinou pela primeira vez a possibilidade de entidades de filantropia se beneficiarem de isenções fiscais por meio } \\
\text { de projetos voltados para o SUS. } \\
\text { Art. 2o - Considera-se entidade beneficente de assistência social, para os fins deste Decreto, a pessoa jurídica de } \\
\text { direito privado, sem fins lucrativos, que atue no sentido de: } \\
\text { IV - Promover, gratuitamente, assistência educacional ou de saúde. [Tendo preferência nos convênios com o SUS]. } \\
\text { Os principais benefícios de imunidade tributária e isenção de contribuições sociais usufruídos pela entidade são: } \\
\text { imposto de renda pessoa jurídica (IRPJ), contribuição provisória sobre a movimentação financeira (CPMF), contribuição } \\
\text { social sobre o lucro líquido (CSLL), cota patronal (INSS), imposto de importação (II), contribuição para o financiamento } \\
\text { da seguridade social (COFINS), imposto sobre serviços de qualquer natureza (ISSQN), imposto territorial urbano (IPTU), } \\
\text { programa de integração social (PIS/PASEP), imposto sobre circulação de mercadorias e prestação de serviços (ICMS) } \\
\text { e outras. Essas isenções são concedidas pela obtenção do Certificado de Entidade Beneficente de Assistência Social } \\
\text { (CEBAS), a partir de critérios definidos neste Decreto, e deve ser renovado a cada } 3 \text { anos. } \\
\text { Art. 3, § 17o - A instituição de saúde [entidade de filantropia] poderá, alternativamente, para dar cumprimento } \\
\text { ao requisito previsto no inciso VI do caput deste artigo ou no § 4o, realizar projetos de apoio ao desenvolvimento } \\
\text { institucional do SUS, estabelecendo convênio com a União, por intermédio do Ministério da Saúde". }\end{array}$ \\
\hline $\begin{array}{l}\text { Decreto no 5.895, } \\
\text { de 08/Ago/2006: Atualiza } \\
\text { a regulamentação das } \\
\text { instituições beneficentes } \\
\text { ou filantrópicas, } \\
\text { especialmente hospitais. }\end{array}$ & $\begin{array}{l}\text { Inclui o parágrafo } 17 \text { do Art. } 3 \text { do Decreto no 2.536, de 07/Abr/1998, com a mesma redação, e define que essas } \\
\text { instituições filantrópicas da saúde (hospitais) devem: } \\
\text { § 4o Ofertar a prestação de todos os seus serviços ao SUS no percentual mínimo de sessenta por cento e comprovar, } \\
\text { anualmente, o mesmo percentual em internações realizadas, medida por paciente-dia. (Redação dada por este } \\
\text { Decreto). } \\
\text { § } 5 \text { o O atendimento no percentual mínimo de que trata o § 4o pode ser individualizado por estabelecimento ou pelo } \\
\text { conjunto de estabelecimentos de saúde da instituição. (Redação dada pelo Decreto no 4.327, de 08/Ago/2002, mantida). } \\
\text { § 7o A instituição de saúde deverá informar, obrigatoriamente, ao Ministério da Saúde, por meio de Comunicação de } \\
\text { Internação Hospitalar - ClH, a totalidade das internações realizadas para os pacientes não usuários do SUS. (Redação } \\
\text { dada pelo Decreto no } 4.327, \text { de 08/Ago/2002, mantida.) }\end{array}$ \\
\hline $\begin{array}{l}\text { Portaria no 3.276, } \\
\text { de 28/Dez/2007: } \\
\text { Regulamenta o início } \\
\text { das atividades de apoio } \\
\text { ao SUS pelas entidades } \\
\text { filantrópicas. }\end{array}$ & $\begin{array}{l}\text { Estabelece que as instituições que optarem por desenvolver projetos de apoio ao desenvolvimento do SUS deverão } \\
\text { atender às etapas de habilitação e de apresentação de projetos. Os primeiros termos de ajuste com essas entidades } \\
\text { foram firmados em } 2008 .\end{array}$ \\
\hline $\begin{array}{l}\text { Lei no } 12.101, \\
\text { de } 27 / \text { Nov/2009 (conhecida } \\
\text { como a Nova Lei da } \\
\text { Filantropia) e Decreto no } \\
\text { 7.237, de 20/Jul/2010 (que } \\
\text { regulamenta essa lei): } \\
\text { Dispõe sobre o processo } \\
\text { de certificação das } \\
\text { entidades beneficentes de } \\
\text { assistência social e regula } \\
\text { procedimentos de isenção } \\
\text { de contribuições sociais. }\end{array}$ & $\begin{array}{l}\text { A lei institui a expressão Hospitais de Excelência para as instituições que participam dos benefícios de isenção fiscal e } \\
\text { de contribuições sociais, indicando que foram habilitadas pelo MS e cumprem os requisitos para a apresentação de } \\
\text { projetos de apoio ao SUS. A denominação indica que essas instituições passam a integrar as ações estratégicas do SUS } \\
\text { de maneira mais intensa por conta do uso otimizado de sua capacidade técnica e conhecimento. } \\
\text { Estabelece como critério alternativo para os Hospitais de Excelência a possibilidade de substituição da obrigatoriedade } \\
\text { de } 60 \% \text { da sua atividade assistencial prestada ao SUS, e remunerada segundo tabela SUS, pela opção de se integrar ao } \\
\text { PROADI-SUS, apresentando projetos cuja somatória financeira não deverá ser inferior ao valor total da isenção fiscal } \\
\text { decorrente da certificação de filantropia. Seis hospitais obtiveram o reconhecimento como Hospitais de Excelência, } \\
\text { sendo cinco da cidade de São Paulo (Hospital Alemão Oswaldo Cruz, Hospital do Coração, Hospital Israelita Albert } \\
\text { Eisntein, Hospital Samaritano e Hospital Sírio Libanês) e um do Rio Grande do Sul (Hospital Moinhos de Vento). }\end{array}$ \\
\hline $\begin{array}{l}\text { Portaria GM/MS no 936, } \\
\text { de 27/Abr/2011: } \\
\text { Dispõe sobre o PROADI- } \\
\text { SUS, coordenação, gestão e } \\
\text { monitoramento/avaliação. }\end{array}$ & $\begin{array}{l}\text { Cria o Comitê Gestor do PROADI-SUS composto por representantes de todas as unidades do Ministério da Saúde, das } \\
\text { Agências - Nacional de Vigilância Sanitária (Anvisa) e Nacional de Saúde (ANS) -, do Conselho Nacional de Secretários } \\
\text { de Saúde (CONASS) e do Conselho Nacional de Secretarias Municipais de Saúde (CONASEMS). Compete ao Comitê a: } \\
\text { (i) definição dos temas e objetivos prioritários; (ii) definição de critérios e requisitos para a comprovação de efetiva } \\
\text { capacidade institucional do Hospital de Excelência; (iii) aprovação da carta consulta; d) avaliação dos resultados dos } \\
\text { projetos de apoio; e (iv) formulação de proposições para aprimoramento do PROADI-SUS. }\end{array}$ \\
\hline
\end{tabular}

Fonte: elaboração própria com base em dados do Departamento de Ciência e Tecnologia, Secretaria de Ciência, Tecnologia e Insumos Estratégicos, Ministério da Saúde 39 (p. 808-9) e consulta às legislações mencionadas nos sites da Presidência da República (http://www.planalto.gov.br/ccivil_03/) e do Ministério da Saúde (http://portalsaude.saude.gov.br/index.php/o-ministerio/principal/secretarias/proadi-sus), ambos acessados em 20/Fev/2017. 
PPP não neoliberal, ainda que sua origem coincida com a implementação dessas políticas. Todavia, preocupa o fato de todo processo de habilitação e seleção de projetos estar nas mãos do Ministério da Saúde, o que torna o programa vulnerável às conjunturas políticas, para o bem e para o mal. A isenção fiscal é significativa, extremamente vantajosa para os Hospitais de Excelência, desobrigados a atender os usuários do SUS, e permanecem dúvidas se esses projetos de fato beneficiam o SUS. Em ambos os casos os custos de transação são altos e há necessidade de aprimorar capacidades e mecanismos de monitoramento contínuo das PPP por parte do Estado.

\section{Para terminar}

A revisão aqui apresentada evidencia mudanças importantes nas relações público-privadas em nível internacional e doméstico, em praticamente todos os setores, com especial ênfase na saúde.

Com base na reflexão teórica de Kamat 1 sobre a privatização do interesse público, pode-se afirmar que as PPP integram a agenda neoliberal privatizadora que vem sendo implementada globalmente. Elas materializam tanto a diminuição do poder de condução da ONU - com a incorporação de poderosas corporações empresariais no seu processo decisório, a dependência de recursos extraorçamentários e de agências financiadoras privadas - quanto a privatização da esfera pública e a deslegitimação do interesse público, por conta da pluralidade de atores admitidos como "representantes da sociedade civil" nos fóruns internacionais, com o mesmo status político e sem qualquer diferenciação. Impera "a noção liberal [clássica] de democracia com seu clamor moral de pluralismo e autonomia" 1 (p. 165) e "na qual o interesse comum é nada além da soma dos interesses privados", pari passu à perspectiva liberal original de sociedade civil "de relações econômicas e sociais que ocorrem por fora do Estado" 1 (p. 167).

Nessa linha de argumentação, o Estado minimalista e a desregulação das relações de produção se tornam necessárias "para estimular o investimento de capital privado e estabelecer relações transnacionais de mercado" 1 (p. 164), delegando a outros atores privados (ou stakeholders como preferem esses ideólogos) as atividades que eram função do Estado: as não lucrativas para ONG ou similares, financiadas com recursos públicos, e as que geram lucros para parceiros privados lucrativos e com financiamento compartilhado. Essa dinâmica exige também uma mudança cultural importante - a incorporação da identidade empresarial, seja na operacionalização/distribuição dos serviços públicos, seja na consciência cidadã, centrada agora nos valores de independência e autonomia (empresarial ou empreendedora) -, o que pressupõe renunciar à noção de direitos sociais 1 .

A ideia de parcerias é um "recurso discursivo central" na implementação dessa agenda, em que os parceiros têm corresponsabilidades - compartilhadas ou consideradas complementares -, sem nenhuma consideração sobre as relações desiguais de poder entre eles ou suas distintas percepções sobre do que significa bens públicos 1 .

Argumenta-se que denominar qualquer interação público-privada como PPP obscurece as distinções que caracterizam esse enfoque na formulação e implantação de políticas. Há que distinguir o tipo de relação e entender os processos de decisão e implementação nos diferentes casos 20 . Arranjos globais (GAVI, RBM, STOP TB, GF, entre outros) operam segundo as políticas e procedimentos de seus financiadores; seus conselhos e grupos de trabalho atuam como órgãos consultivos da direção. Embora o representante da agência multilateral "hospedeira" tenha poder de veto sobre as ações das PPP, qualquer um dos parceiros tem o direito de ignorar as decisões do conselho quando não lhe agradam ou não lhe convêm. Portanto, as relações aí estabelecidas são assimétricas e vão depender do poder real de cada parceiro envolvido na PPP 20. Na esfera doméstica, as PPP podem ser implementadas de distintas maneiras, dependendo da especificidade de cada país e dos arranjos negociados. Contudo, sua efetividade depende de inúmeros fatores e a diferença de poder entre os parceiros também é evidente.

Essa agenda política em implementação há décadas vem articulando os níveis global e doméstico (ou local), "de forma a produzir efeitos comuns mutuamente potencializadores"; para tal, "as relações público/ privado têm sido reconstituídas a partir de uma miríade de instituições econômicas, sociais e políticas” 1 (p. 170), e seus significados vêm sendo "rearticulados" nas práticas institucionais, globais e nacionais. "É necessário, portanto, problematizar a dissolução dos significados de público e de privado que está incorporada no discurso da governança global” 1 (p. 167), assim como nas "inovações” das políticas nacionais de saúde. 
Sabe-se que a articulação público-privada é estrutural nos sistemas de saúde, mas as PPP contemporâneas são radicalmente diferentes. Os distintos tipos de interação e a complexidade de sua implementação exigem um Estado forte e capacitado para atuar ativa e energicamente em todas as etapas de sua implementação e avaliação, o que não é o caso na maioria dos países do Sul global, em que o subfinanciamento setorial configura essas práticas como genuínas delegações. Os longos períodos concessionados incluem riscos em si, relacionados a possíveis descontinuidades, seja pelas mudanças de governo e escassez conjunturais de recursos, seja por mudança dos próprios parceiros privados, ou desinteresse, ao longo do tempo. A ênfase nos hospitais como objeto das PPP evidencia o paradigma biomédico da agenda neoconservadora, focada na assistência médica, que desqualifica outras formas de cuidados em saúde e a proteção social 3,16 .

Não se pretende com esta revisão elaborar conclusões, mas enfatizar a importância de aprofundar a reflexão sobre esse tema para subsidiar os debates setoriais, sobretudo na conjuntura restritiva e ameaçadora atual, em todo o mundo. Reitera-se a necessidade de não subestimar o poder, remodelado e reforçado, desses atores privados, assim como a dificuldade de deslocá-los desse lugar político, uma vez incrustados nele, seja nas organizações multilaterais, seja nos sistemas de saúde em nível nacional, o que exige repensar as estratégias para preservar direitos conquistados com lutas seculares.

\section{Agradecimentos}

Ao Conselho Nacional de Desenvolvimento Científico e Tecnológico (CNPq) pela Bolsa de Produtividade em Pesquisa concedida à C. Almeida. À Fundação de Amparo à Pesquisa do Estado do Rio de Janeiro (Faperj), cujo apoio financeiro possibilitou a pesquisa da qual este Ensaio é caudatário. Aos/às revisores/as anônimos/as que contribuíram para o aprimoramento deste Ensaio. Obviamente qualquer equívoco ou má interpretação é de minha inteira responsabilidade.

\section{Referências}

1. Kamat $\mathrm{S}$. The privatization of public interest: theorizing NGO discourse in a neoliberal era. Rev Int Polit Econ 2004; 11:155-76.

2. Torchia M, Calabró A, Morner M. Public-private partnerships in health care sector: a systematic review of the literature. Public Management Review 2015; 17:236-61.

3. Almeida C. Os modelos de reforma sanitária dos anos 80: uma análise crítica. Saúde Soc 1996; 5:3-53.

4. Almeida C. Reforma do estado e reforma de sistemas de saúde: experiências internacionais e tendências de mudança. Ciênc Saúde Coletiva $1999 ; 4: 263-86$.

5. Schäferhoff M, Campe S, Kaan C. Transnational public-private partnerships in international relations: making sense of concepts, research frameworks, and results. International Studies Review 2009; 11:451-74.

6. Buse K, Walt G. Global public-private partnerships: part I - a new development in health? Bull World Health Organ 2000; 78:549-61.

7. Buse K, Walt G. Global public-private partnerships: part II - what are the health issues for global governance? Bull World Health Organ 2000; 78:699-709.

8. Buse K, Harmer A. Power to the partners? The politics of public-private health partnerships. Development 2004; 47:49-56.

9. Ruckert A, Labonté R. Public-private partnerships (PPPs) in global health: the good, the bad and the ugly. Third World Q 2014; 5:1598-614. 
10. Almeida CC. O Banco Mundial e as reformas contemporâneas do setor saúde. In: Pereira JMM, Pronko M, organizadores. A demolição de direitos: um exame das políticas do Banco Mundial para a educação e a saúde (19802013). Rio de Janeiro: Escola Politécnica de Saúde Joaquim Venâncio, Fundação Oswaldo Cruz; 2014. p. 183-232.

11. Almeida C. Saúde, política externa e cooperação Sul-Sul em saúde: elementos para a reflexão sobre o caso do Brasil. In: Gadelha P, Carvalho JN, Pereira TR, organizadores. Saúde no Brasil em 2030: diretrizes para a prospecção estratégica do sistema de saúde brasileiro. Rio de Janeiro: Fundação Oswaldo Cruz/Ministério da Saúde/Secretaria de Assuntos Estratégicos da Presidência da República/Instituto de Pesquisa Econômica Aplicada; 2013. p. 233-327.

12. Pereira JMM. O Banco Mundial e a construção político-intelectual do combate à pobreza. Topoi 2010; 11:260-82.

13. Lee K, Kamradt-Scott A. The multiple meanings of global health governance: a call for conceptual clarity. Global Health 2014; 10:28.

14. Viegas LL. A reforma da Organização Mundial da Saúde: processo, tendências atuais e desafios (1998-2014) [Dissertação Mestrado]. Rio de Janeiro: Escola Nacional de Saúde Pública Sergio Arouca, Fundação Oswaldo Cruz; 2014.

15. World Bank. The state in a changing world overwiew. Washington DC: World Bank; 1997.

16. Almeida C. Reforma de sistemas de saúde: tendências internacionais, modelos e resultados. In: Giovanella L, organizadora. Políticas e sistemas de saúde no Brasil. 2a Ed. Rio de Janeiro: Editora Fiocruz; 2012. p. 871-922.

17. Nelson J. Building partnerships: cooperation between the United Nations system and private sector. Report Commissioned by the United Nations Global Compact. New York: UN Department of Public Information; 2002.

18. Organisation for Economic Co-operation and Development. Shaping the 21st century: the contribution of development cooperation. Paris: Organisation for Economic Co-operation and Development; 1996.

19. Kickbush I, Quick J. Partnerships for health in the 21st century. World Health Stat Q 1998; 51:68-74.

20. Richter J. Public-private partnerships and international health policy-making: how can public interests be safeguarded? Helsinki: Hakapaino Oy; 2004.

21. Mezzalana F, Ouedraogo LD. Private sector involvement and cooperation with the United Nations system. Geneva: Join Inspection Unit, United Nations; 1999.

22. Yamey G. WHO in 2002: have the latest reform reversed WHO's decline? BMJ 2002; 325:1107-12.

23. Sridhar D. Who sets the Global Health Research Agenda? The challenge of multi-bi financing. PLoS Med 2012; 9:e1001312.
24. Oliveira GHJ. Parceria público-privada e direito ao desenvolvimento: uma abordagem necessária. Revista Eletrônica de Direito Administrativo Econômico 2005; (3). http://www. direitodoestado.com.br/artigo/gustavo-hen rique-justino-de-oliveira/parceria-publicoprivada-e-direito-ao-desenvolvimento-umaabordagem-necessaria.

25. André C, Hermann C. Privatisation of health care in Europe. Vienna: Working Life Research Centre; 2013.

26. Almeida C. Reforma de sistemas de servicios de salud y equidad en América Latina y el Caribe: algunas lecciones de los años 80 y 90 . Cad Saúde Pública 2002; 18:905-25.

27. Vicente-Fuentes F. Colaboración publico privada en la gestión de los centros y servicios sociosanitarios: experiencias en Europa y en España. Cartagena: Instituto de Mayores y Servicios Sociales; 2015.

28. Yepes FJ. ¿Por qué la crisis multisistémica de la salud? Rev Gerenc Políticas Salud 2013; 12:5-7.

29. Londoño JL, Frenk J. Structured pluralism: towards a new model for health system reform in Latin America. Washington DC: Technical Department for Latin America and the Caribbean, World Bank; 1995.

30. Arteaga-Herrera O. El dificil camino desde el diseño a la implementación de las reformas de salud. Rev Chil Salud Pública 2004; 8:39-43.

31. Comisión Asesora Presidencial para el Estudio y Propuesta de un Nuevo Marco Jurídico para el Sistema Privado de Salud. Informe final. Santiago: Gobierno de Chile; 2014.

32. Bustamante AV, Méndez CA. Health care privatization in latin america: comparing divergent privatization approaches in Chile, Colombia, and Mexico. J Health Polit Policy Law 2014; 39:841-86.

33. Llumpo A, Montagu D, Brashers E, Foong S, Abuzaineh N, Feachem R, et al. Lessons from Latin America: the early landscape, of healthcare public-private partnerships. San Francisco: Global Health Group; 2015. (Healthcare Partnerships Series, 2).

34. Londoño JL. Estructurando pluralismo en los servicios de salud: la experiencia colombiana. Revista de Análisis Económico 1996; 11:37-60.

35. Barbosa AP, Malik AM. Desafios na organização de parcerias público-privadas em saúde no Brasil. Análise de projetos estruturados entre janeiro de 2010 e março de 2014. Rev Adm Pública 2015; 49:1143-65.

36. Mânica FB. Parcerias público-privadas no setor da saúde: um panorama das concessões administrativas no Brasil e no mundo. In: Avanza CS, Franco FC, Schulman G, Gebran Neto JP, Gentilli RML, organizadores. Direito da saúde em perspectiva: Judicialização, gestão e acesso. Vitória: Editora Emescam; 2016. p. 215-52.

37. Brasil. Lei no 11.079 , de 30 de dezembro de 2004. Institui normas gerais para licitação e contratação de parceria público-privada no âmbito da administração pública. Diário Oficial da União 2004; 31 dez. 
38. Carrera MBM. Parceria público-privada na saúde no Brasil: estudo de caso do Hospital do Subúrbio de Salvador - Bahia [Dissertação de Mestrado]. São Paulo: Escola de Administração de Empresas de São Paulo, Fundação Getúlio Vargas; 2012.

39. Departamento de Ciência e Tecnologia, Secretaria de Ciência, Tecnologia e Insumos Estratégicos, Ministério da Saúde. Programa de Desenvolvimento Institucional do Sistema Único de Saúde. Rev Saúde Pública 2011; 45:808-11.
40. Ministério da Saúde. Relatório final: oficina de avaliação do 1o ciclo do PROADI-SUS. Brasília: Ministério da Saúde; 2013.

41. Giovanella L, Stegmüller K. Crise financeira europeia e sistemas de saúde: universalidade ameaçada? Tendências das reformas de saúde na Alemanha, Reino Unido e Espanha. Cad Saúde Pública 2014; 30:2263-81.

\section{Abstract}

This essay addresses several dimensions that promote and consolidate the growing participation by private stakeholders in the decision-making process in health, emphasizing international and domestic factors that have facilitated and sustained the persistence of the neoliberal political and ideological perspective over the course of nearly thirty years (since the 1990s). The article emphasizes the role of intergovernmental organizations in this process, highlighting public-private interactions at the global and domestic levels, with a specific focus on so-called public-private partnerships (PPPs). The working premise is that such linkages alter the power relations in policy formulation and implementation, with a predominance of private stakeholders. The article presents an overview of the development of PPPs in Europe, Latin America, and Brazil, identifying their specific origins and the simultaneity of triggering events. The text reiterates the importance of not overlooking the power of these actors in dislodging them from this political position, whether in multilateral organizations or national health systems. The aim is to emphasize the importance of more in-depth reflection on the subject, backing debates within the sector. This entire dynamic requires rethinking strategies of resistance to preserve the rights won through centuries of struggle.

Public-Private Sector Partnerships; Health Systems; Health Services; Health Policy

\section{Resumen}

Este ensayo se propone discutir algunas dimensiones que impulsan y consolidan la creciente participación de agentes privados en el proceso de toma de decisiones en el ámbito de la salud, poniendo énfasis en los elementos internacionales y nacionales que promueven y sostienen el mantenimiento de la perspectiva político-ideológica neoliberal en este sector, a lo largo de casi treinta años (desde los años 1990). Se destaca el papel de organizaciones intergubernamentales en este proceso, dando como resultado interacciones público-privadas en el ámbito global y nacional, sobre todo en las denominadas colaboraciones público-privadas (CPP). Se parte de la premisa que tales asociaciones alteran las relaciones de poder en la formulación e implementación de políticas, con un predominio de los agentes privados. Se presenta un breve panorama del desarrollo de las CPP en Europa, en Latinoamérica y en Brasil, rescatándose sus orígenes específicos y la simultaneidad de los eventos desencadenantes. Se reitera la importancia de no ignorar el poder de estos actores, así como la dificultad de desalojarlos de este espacio politico, una vez involucrados en el proceso decisorio, sea en organizaciones multilaterales, sea en sistemas de salud a nivel nacional. La pretensión es resaltar la importancia de profundizar en las reflexiones sobre este asunto, apoyando los debates sectoriales. Toda esta dinámica exige repensar estrategias de resistencia para preservar los derechos conquistados a lo largo de siglos mediante luchas.

Asociaciones entre el Sector Público y el Privado; Servicios de Salud; Sistemas de Salud; Politica de Salud

Recebido em 16/Nov/2016

Versão final reapresentada em 13/Mar/2017

Aprovado em 23/Mar/2017 